\title{
Risky Sexual Behaviours of Gender and Sexual Minorities
}

\author{
Belpatra Nath Yogi*
}

\begin{abstract}
The article aims to explore the experiences on the risky sexual behaviours of the gender and sexual minorities in Surkhet district. It is a narrative study based on interview data. Thirtyseven sexual minorities selected through snowball sampling were interviewed and the data were analysed using thematic framework approach. The gender and sexual minorities involve in sexual activity before their maturation at the age below 20 . They have multiple sexual partners and have active sex life preferring anal and oral sexes the most. Many of them do not use condom in every sexual contact, do not visit health institutions for regular check-up, and do not test for HIV and other STDs which make them more vulnerable to diseases and poor health. They have made their sexual behaviours at more risk by their sexual involvement with drug users and their monetary involvement in sex. There is diversity in sexual orientations and behaviours among them. So an extensive and in-depth study in this issue is urgently required for the fuller understanding of socio-demographic influence on risky sexual behaviours of sexual minorities.
\end{abstract}

Key Words: Diversity in sex, Gender and sexual minorities, multiple sexual partners, risky sexual behaviours

\section{Introduction}

Sexual minorities are a group whose sexual identity, orientation or practices differ from majority of the surrounding society. The term "sexual minorities" refers to individuals whose sexual orientation is outside the heterosexual mainstream (Crehan \& McCleary-Sills, 20I5). Usually, sexual minorities comprise of lesbian, gay, bisexual and transsexual/transgender (LGBT) individuals. LGBT is the standard term used by the United Nations to refer to people with non-traditional sexual orientations and gender identities (UNDP/USAID, 20I4).

Risky sex is defined as sex with multiple partners, sex without using condom and sex later regretted due to alcohol use (Agius, Taft, Hemphill, Toumbourou, \& McMorris, 2013). Risky sexual behaviour is defined as any behaviour that increases the negative consequences or risk of sexually transmitted infections and unintended pregnancies which include early sexual activity, having multiple sex partners, having sex while using alcohol or drugs, and unprotected sexual behaviours (Centres for Disease Control and Prevention, 2010; Cooper, 2014).

LGBT people all over the world continue to face challenges. There are 83 countries and territories in the world that criminalize LGBT activities and relationships and seven countries institute the death penalty for same-sex relationships (ILGA, 20/4). Nepal is a largely

\footnotetext{
* PhD Scholar, Graduate School of Education, TU, Lecturer, Surkhet Campus (Education), Birendranagar, Surkhet E-mail: bnyogiskt@gmail.com
} 
patriarchal society and does not easily accept people of diverse sexual orientations (Greene, Robles, \& Pawlak, 2012). So, in Nepal, many people seek to hide same sexual desire and relationships or gender-variant practices (Coyle \& Boyce, 2015). The sexual minorities face a myriad of obstacles like discrimination and mistreatment by security forces, sexual assault, harassment, physical violence, physical and psychological threats to emotional trauma such as exclusion from their families and from society (National Human Rights Commission of Nepal, 2013). They are sexually harassed and discriminated while in the process of recruitment and employment (UNDP/ USAID, 20I4). They are even not safe within their families too. These minority people have become the victims of human rights violations and thus represent as a vulnerable group (National Human Rights Commission of Nepal, 2013) in Nepal.

The Yogyakarta Principles on human rights in relation to sexual orientation and gender identity (Amnesty International, 20I4) enshrine the idea that gender recognition should be based on self-identification of the people instead of the decisions by courts or medical professionals (Young, 2016). But the self-identification with homosexuality is very difficult due to pressures from the family members and traditional norms of the society, which can lead to forced marriages with the partner of the opposite sex (Khadka, 2017), and thus hide their gender identity and sexual orientation (National Human Rights Commission of Nepal, 20I3). In such a situation, identification of the sexual minorities in a community is really a challenge.

LGBT populations have not been considered as priority research populations in Nepal (Regmi \& Teijlingen, 2015). The data on Lesbian, Gay, Bisexual and Transsexual individuals in Nepal is low (Khadka, 2017). It shows the inadequacy of research in the field of sexual minorities which is more apparent in the remote areas and outside the Kathmandu valley because most of these studies are focused within Kathmandu valley (FHI \& BDS, 200I; Greene, 20I5; Sharma, 20I6). The studies are mainly focused on the LGBT rights and movement in Nepal (Blue Diamond Society/Heartland Alliance, 2013; Knight, 20I5; Young, 2016; Khadka, 2017), knowledge on sexual and reproductive health including HIVIAIDS (UNDP/Williams Institute, 20I4; Sharma, 2016), and the social and economic issues (Boyce \& Coyle, 2013; Coyle \& Boyce, 20I5; Blue Diamond Society, 2018) of the sexual minorities; but a little work is done in the behavioral aspect of the sexual minorities. There is lack of adequate researches on LGBT lives and history in Surkhet and more specifically the risky sexual behaviours of the sexual minorities. So this study focuses to explore the experiences of the sexual minorities on their risky sexual behaviours.

\section{Methods}

It is a narrative study based on interview data. The snowball sampling was used to identify all possible thirty-seven sexual minorities who were living in Surkhet district for minimum a year were interviewed during November to December 2018. The participants were from different socio-economic backgrounds and informed verbal consent was taken before the interview. The data collected through a semi-structured interview guideline was analysed through a thematic framework approach. 


\section{Results and Discussion}

Five relevant themes on the risky sexual behaviours of the sexual minorities emerged after analysing the interview data based on the variables like first experience of sex, number of sex partners, types of sex, use of condom, drug users as sex partners, money for sex, use of alcohol, and health examination. They are - early sexual activity, multiple sexual partners, diversity in sexual orientation and behaviours, drugs, alcohol and money for sex, and risk of sexually transmitted diseases (STDs).

\section{Early Sexual Activity}

When asked about the age of the sexual minorities when they had the first sex, they had a number of different responses but it was generally before their maturation at the age below 20. Among the thirty-seven participants, two of them replied that they had the first sex when they were just nine years. They said "it was very painful experience and against our will but we did not complain." One of them also said, "It was bleeding from my anus...I was confused what to do". It means that they were sexually abused but could not complain it to others, even to their family members too. The state of confusion in such situation indicates their immaturity and lack of attachment to their parents and other family members. Similarly, the minority people are at the conflicting situations between their own minority values and the dominant values of the public which lead them towards stress processes including experiences of prejudice, fear of rejection, hiding, concealing and internalized homophobia as described in minority stress model (Meyer, 2003) so they cannot easily share their feelings and problems with other people which increase the risk of repeating such behaviours. First sex at an early age is seen linked with life course engagement in risky sexual behaviours which is expected to be associated with increased risk of unintended pregnancies, STDs, and increasing number of sexual partners (Scott, Wildsmith, Welti, et al,, 20II) but the sexual minorities during their earlier sexual activities were not aware of these problems and were at the risk of life threatening problems like STDs and HIVIAIDS.

\section{Multiple Sexual Partners}

All the sexual minorities had multiple sexual partners except lesbians. The number of sexual partners ranged from two to more than twenty too. A few of them were even unable to count the exact number of sexual partners due to their sexual contact with a large number of sexual partners as they recalled, "I cannot count all of them, may be as many as thirty."

Nearly half of them had the number between six to twenty. But the lesbians replied that they were faithful with their single sexual partners and wanted to pass their life with them. All the sexual minorities were found involved in sex with their sexual partners that shows their active sexual life but involving in multiple sexual partners is a risky sexual behaviour as it increases the risk of diagnosing STDs (Scott, et al., 20I I). 


\section{Diversity in Sexual Orientation and Behaviours}

The sexual minorities were found involving in different types of sex - oral sex, anal sex, vaginal sex, and other types of sexual activities like rubbing vulva, kissing and so on. But the types of sex they preferred most was oral and anal sexes although three of them replied that they had vaginal sex with their opposite sex partners too. The lesbians answered that they perform a number of sexual activities but mostly prefer oral sex and rubbing vulva. The gays claimed the anal sex as the most preferred type of sex but the transsexuals answered to prefer the oral and anal sexes equally. Though the bisexuals were found involving in vaginal sex too, they replied preferring the anal and oral sexes the most. It shows their multiple, overlapped and complex roles which reveal the multiple identities and complexities in sexual orientation and behaviours of the sexual minorities (Galupo, et al., 2015) which accelerates the risk of getting infections and diseases.

\section{Drugs, Alcohol and Money for Sex}

All the sexual minorities replied that they never used drugs and many of them claimed that they did not have sex with drug users but some of them were not sure whether all of their sex partners were non-users or not. At the same time, six of them claimed that they had sex with drug users too. One of these six participants recalled, "After we had a pleasurable sex, my partner mixed a small piece of something with cigarette and smoked it. He asked me to enjoy it but I didn't. Later on, he replied me that it was Ganja (marijuana)."

It means that they were not only at the risk of using drugs but also vulnerable to sexually transmitted diseases and infections which is also supported by a study that revealed that these people are at higher risk of substance misuse and deliberate self-harm than heterosexual people (King et al., 2008).

They were also asked about the use of alcohol which revealed the mixed responses. Nearly half of them replied that they never used alcohol but many of them were the occasional users of alcohol though two of them replied that they were the regular users. The alcohol users also revealed that they had many sexual encounters while drinking alcohol. The previous epidemiological findings clearly support the strong interrelationships between alcohol and other substance use and risky sexual behaviours with adverse outcomes like STDs (Windle, Sales, \& Windle, 2013). So, the sexual minorities using alcohol were at the risk of STDs and HIVIAIDS.

The sexual minorities had no commercial motive for sex though six of the participants recalled that they accepted money after indulging sex with the sex partners. One of these participants recalled, "I've a sex partner who usually gives me money after sex but I never forced him to pay". The next one replied, "Some of my sex partners give me some money; I do not feel good to receive it but I need it." The next others also have similar voices which reveal that they are not the sex workers; they do it to meet their sex desires or to satisfy their sex partners only. Though there is no commercial motive for sex, there is the possibility of commercialization in sex among them as they have accepted money for sex. 


\section{Risk of Sexually Transmitted Diseases}

Among all the 37 participants, 17 of them had no infection of HIV and STDs as they tested for it but the next others had never tested for HIV and STDs who are at risk of such infections. It shows that there are different challenges in accessing the testing of HIV and STDs as in a study of Canada that found a number of barriers in testing HIV and sexually transmitted infections among trans men (Scheim \& Travers, 2016). Almost all of them replied that they visited health institutions only after getting sick where one of them said that she visits hospital regularly in every six month for health examination. It reveals that they do not have regular health check up against HIV and STDs which creates an unknown environment for infections and diseases and may accelerate HIV and STDs. Though all of them replied that they used condom during sexual contact, still few of them are occasional users only. It means that the possibility of transferring HIV and other STDs among them is still prevalent and their health is at risk as a study shows that transgender people are one of the most affected by the HIV epidemic and are 49 times more likely to be living with HIV than the general population (UNAIDS, 20I6). That's why they need to visit health institutions regularly, but the present study shows their irregular health behaviour of visiting health institution and examining their health. The reasons behind it may be a number of factors like low awareness level, less access to health services, low socioeconomic status, and so on.

\section{Conclusion}

Sexual minorities are a group whose sexual identity, orientation or practices differ from majority of the surrounding society which comprise of lesbian, gay, bisexual and transsexual/transgender individuals. Risky sexual behaviour refers to behaviour that increases one's risk of contracting sexually transmitted infections and experiencing unintended pregnancies. The sexual minorities involve in sexual activity before their maturation at the age below 20. They have multiple sexual partners and have active sex life preferring anal and oral sexes the most, so the sexual behaviour is at risk. Furthermore, many of them do not use condom in every sexual contact with their sex partners, do not visit health institutions for regular check up and do not test for HIV and other STDs which make them more vulnerable to diseases and poor health. They have made their sexual behaviours at more risk by their sexual involvement with drug users and monetary involvement in sex. There are multiple sexual orientations and identities among them, so complexities in understanding their sexual behaviours which demands both extensive and in-depth study in this issue. 


\section{References}

Agius, P., Taft, A., Hemphill, S., Toumbourou, J., \& McMorris, B. (2013). Excessive alcohol use and its association with risky sexual behaviour: A cross-sectional analysis of data from Victorian secondary school students. Australian and New Zealand Journal of Public Health, 37, 76 - 82. doi: 10.1 III/1753-6405.12014

Amnesty International. (20I4). LGBT rights: The Yogyakarta principles. Retrieved September 10, 2018 from https://www.amnestyusa.org/pdfs/YogyakartaPrinciples.pdf

Blue Diamond Society. (2018). Discrimination and violence against lesbian and bisexual women and transgender persons in Nepal. Retrieved September 12, 2018 from https://tbinternet.ohchr.org/Treaties/CEDAW/Shared\%20Documents/NPL/INT_CEDAW _NGO_NPL_30008_E.pdf

Blue Diamond Society/Heartland Alliance. (2013). The violations of the rights of lesbian, gay, bisexual, transgender, and intersex persons in Nepal. Retrieved September II, 2018 from https://tbinternet.ohchr.org/Treaties/CCPR/Shared\%20Documents/NPL/INT_CCPR_NG O_NPL_14738_E.pdf

Boyce, P. \& Coyle, D. (2013). Development, discourse and law: Transgender and same-sex sexualities in Nepal. Retrieved September II, 2018 from http://www.ids.ac.uk/publication/

Centers for Disease Control and Prevention (2010). Youth Risk Behavior Surveillance-United Sates, 2009. MMWR, 59 (SS-5). Retrieved from http://www.cdc.gov/mmwr/preview/ mmwrhtml/ss5905al.htm

Cooper, M. L. (20I4). Alcohol use and risky sexual behavior among college students and youth: Evaluating the evidence. Journal of Studies on Alcohol. doi: 10.15288/jsas.2002.s I4.10I

Coyle, D. \& Boyce, P. (2015). Same-sex sexualities, gender variance, economy and livelihood in Nepal: exclusions, subjectivity and development. Retrieved September 12, 2018 from https://opendocs.ids.ac.uk/opendocs/bitstream/handle/ I23456789/5773/ER I09

Crehan, P. \& McCleary-Sills, J. (20I5). Brief on violence against sexual and gender minority women. Violence against women and girls: A resource guide. Retrieved September 10, 2018 from http://www.vawgresourceguide.org/sites/default/files/briefs/vawg_resource_guide_ sexual_and_gender_minority_women_final.pdf

Family Health International [FHI] \& Blue Diamond Society [BDS]. (200I). Rapid ethnography of male to female sexuality and sexual health. Kathmandu: FHI. Retrieved from www.hivpolicy.org

Galupo, M. P., Mitchell, R. C., \& Davis, K. S. (2015). Sexual minority self-identification: Multiple identities and complexity. Psychology of Sexual Orientation and Gender Diversity, 2(4), 355364. Retrieved from http://psycnet.apa.org/record/20I5-38665-00I

Greene, M., Robles, O., \& Pawlak, P. (2012). Masculinities, social change, and development. Washington, DC: World Bank Group. 
Greene, S. (2015). Gender and sexuality in Nepal: The experiences of sexual and gender minorities in a rapidly changing social climate. Retrieved September II, 2018 from https://digitalcollections.sit.edu/isp_collection/2093

International Lesbian, Gay, Bisexual, Trans and Intersex Association (ILGA). (20I4). Statesponsored homophobia: A world survey of laws: Criminalization, protection and recognition of same-sex love. Retrieved from old.ilga.org

Khadka, P. (2017). Understanding LGBT rights in Nepal. Retrieved September 10, 2018 from https://www.ucanews.com/news/understanding-lgbt-rights-in-nepal-/77966

King, M., Semlyen, J., Tai, S., Killaspy, H., Osborn, D., Popelyuk, D., \& Nazareth, I. (2008). A systematic review of mental disorder, suicide, and deliberate self harm in lesbian, gay and bisexual people. BMC Psychiatry, 8(70). Retrieved September 10, 2018 from https://bmcpsychiatry.biomedcentral.com/articles/I0.1 I86/I47/ -244X-8-70

Knight, K. (20I5). Bridges to justice: Case study of LGBTI rights in Nepal. Retrieved September II, 2018 from http://www.astraeafoundation.org/uploads/files/Astraea\%20Nepal\%20Case\% 20Study.pdf

Meyer, I.H. (2003). Prejudice, social stress, and mental health in lesbian, gay and bisexual populations: Conceptual issues and research evidence. Psychological Bulletin, 129, 674-697. doi:10.1037/0033-2909.129.5.674

National Human Rights Commission of Nepal. (2013). Report to the regional national human rights institutions project on inclusion, the right to health and sexual orientation and gender identity. Rome: The International Development Law Organization (IDLO). Retrieved September II, 2018 from http://www.asia-pacific.undp.org/content/dam/rbap/docs/ Research\%20\&\%20Publications/hiv_aids/rbap-hhd-2013-nhri-project-on-right-to-healthsogi-nepal.pdf

Regmi, P. R. \& Teijlingen, E. (20I5). Importance of health and social care research into gender and sexual minority populations in Nepal. Asia-Pacific Journal of Public Health, 27(8), 806808. doi: $10.1177 / 1010539515613413$

Scheim, A. I. \& Travers, R. (20I7). Barriers and facilitators to HIV and sexually transmitted infections testing for gay, bisexual, and other transgender men who have sex with men. AIDS Care, 29(8), 990-995. doi: 10.1080/09540121.2016.1271937

Scott, M. E., Wildsmith, E., Welti, K., Ryan, S., Schelar, E., \& Steward-Streng, N. R. (20II). Risky adolescent sexual behaviours and reproductive health in young adulthood. Perspectives on Sexual and Reproductive Health, 43 (2), II0-1 I8. doi: 10.1363/43 I I0II

Sharma, S. (2016). Knowledge and attitude regarding HIVIAIDs among sexual minorities of Kathmandu. Journal of Kathmandu Medical College, 5(I7). Retrieved September 10, 2018 from https://www.nepjol.info/index.php/JKMC/article/viewFile//84I8//4990

UNAIDS. (2016). Prevention gap report. Retrieved from http://www.unaids.org/sites/default/ files/media_asset/2016-prevention-gap-report_en.pdf 
UNDP/USAID. (20I4). Being LGBT in Asia: Nepal country report. Bangkok: Author. Retrieved from http://asia-pacific.undp.org

UNDP/Williams Institute. (2014). Surveying Nepal's sexual and gender minorities: An inclusive approach. Bangkok: UNDP.

Windle, M., Sales, J. M., \& Windle, R. C. (2013). Influence of alcohol and illicit drug use on sexual behavior. In D. S. Bromberg \& W. T. O'Donohue (Eds.), Handbook of child and adolescent sexuality, (Pp. 253-274). doi: https://doi.org/I0.1016/B978-0-I2-387759-8.000I0-6

Young, H. (2016). Trans rights: Meet the face of Nepal's Progressive third gender movement. The Guardian. Retrieved September 10, 2018 from https://www.theguardian.com/ 